\title{
It is Necessary to React
}

The Brazilian scientific community was strongly shaken by a public note released on August $1^{\text {st }} 2018$, signed by the President of CAPES and addressed to the Minister of Education, from which the agency is directly subordinated, alerting that the budget for the agency proposed by the government for the year of 2019 is so short that if approved, it would represent the interruption of practically all the CAPES commitments from August, 2019. This includes the payment of 93 thousands scientific scholarships for masters and $\mathrm{PhD}$ students; the payment of 350 thousands of beneficiaries directly engaged on different programs dedicated to improve the teaching in the secondary level in Brazil; the funds for the maintenance of scientific programs related to the international collaboration between scientists from Brazil and different countries around the world; among others. As if that were not enough, just a few days after the other two Brazilian agencies directly related to the financing of Science, Technology and Innovation (S,T\&I), $\mathrm{CNPq}$ and FINEP, released notes also signed from their Presidents warning that the cuts of the budget proposed for 2019 will freeze any possibility of investments in S,T\&I in the next year.

The Brazilian science is mostly supported by these three governmental agencies, and these announcements alert for the real possibility of a crash in the entire Graduate system in Brazil, which is one of the most successful, respectable and continued State Program in this country, responsible for graduating approximately 61000 masters and 22000 doctors each year. Moreover, the drastic cut in the agencies' budget represents a huge putsch in the development of the Science and Technology in Brazil, a strategic area that have been sidelined by the political authorities in the past recent years, with its apex represented by the extinction of the Federal Ministry of Science, Technology and Innovation in 2016 (which was fused to the Ministry of Communications) followed by a drastic reduction of priorities and investments.

There are two things that get our attention in the episodes of the Brazilian agencies' notes: first, they are the government publically alerting to the own government that something needs to be urgently modified, which makes them more serious; second, apparently they finally awakened the main actors (professors, scientists, students, technicians) from the inexplicable lethargy they were affected. Why was the scientific community in Brazil so quiet, in spite of all the difficulty it was suffering? Certainly there are several different answers to this question, some probably related to the great difficult and delicate political moment that Brazil is currently experiencing. Another answer could be related to the consensus that the scientists in Brazil feels perfectly well represented by their scientific societies and organizations, such as the Brazilian Society for the Progress of Science (SBPC) and the Brazilian Academy of Sciences (ABC), which are strongly engaged to reverse the negative scenario.
The Brazilian Chemical Society (SBQ) has been in the battle front in the fight against the budget crush for S,T\&I. Also, SBQ has been anticipating the discussion and proposing solutions. In the $41^{\text {st }}$ Annual Meeting of SBQ in May 2018, the main theme picked up by the board of SBQ was "building the tomorrow", demonstrating the SBQ's concerns regarding our future. Among several activities, the central symposium of the meeting gathered the President of SBQ (Prof Aldo J.G. Zarbin), the President of SBPC (Prof Ildeu Castro Moreira), one representative of CNPq (Prof Marcelo Morales) and one representative of the SENAI Innovation Institute, which is an institute of applied research connected to the Brazilian industry (Dr Paulo Coutinho). During two and a half hours they presented to a large audience their diagnostic (supported by numbers, data, examples, study of cases), and proposed several solutions, unconditionally passing by the increase in the public investments in $\mathrm{S}, \mathrm{T} \& \mathrm{I}$.

There are no exact recipes on how to leave from an economic crisis, but there are well known actions to do it. A strong public investment in science and technology is a consensus. Several countries such as China, Korea, USA, Russia and India, among others, have been increasing their public investments in S,T\&I as a strategy to accelerate their economies. Recent reports from UNESCO ${ }^{1}$ and International Monetary Fund ${ }^{2}$ have demonstrated the unequivocal relationship between the GDP (gross domestic product) of a country and their scientific development (measured by the numbers of scientists, PhDs, scientific production and public investments). Several studies reported that public support for S,T\&I is essential, since the social rate of return exceeds the private rate one. ${ }^{3}$ Also, it has been demonstrated that the economic rates of return are in the range of $20-50 \%$. So, besides the strong social and strategic character, the public investments in S,T\&I also gives economic return. The natural question which arises is: why is Brazil going to the opposite way?

The argument on the necessity of cuts and adjustments in the public spending due to the economic crisis does not convince. It would be convincing for some people if that control was sprayed over all the public sectors, but it does not happen. While the sectors of S,T\&I and Education suffers drastic cuts, non-strategic and political areas are privileged, and huge debts of large corporations are forgiven. Clearly, it is a matter of political choice.

Another argument that does not find grounds is that the population is not interested in this subject, and public investments should be deviated to other areas. Again, the reality is exactly the opposite. In a recent study ${ }^{4}$ released by the Center of Management and Strategic Studies (CGEE), an organism directly associated to the Ministry of Science, Technology, Innovation and Communication of the Federal Government, different aspects related to the public perception of Science and Technology in Brazil have been presented and 
discussed. In 2015, 61\% of the Brazilian population declared to be interested in aspects related to Science and Technology, a percentage higher than the ones interested by sports $(56 \%)$, politics $(27 \%)$, arts and culture $(57 \%)$, for example. The number is higher than observed in the European Union (53\%). According to the same study, $73 \%$ of the Brazilians believe that Science and Technology brings only benefits or much more benefits than damage to the humankind, a more positive view than in other countries such as USA (67\%), Spain (64\%), France $(43 \%)$, German (43\%) and UK (41\%), for example. Also, in a so-called "trust index", which considers the balance of positives and negatives aspects of different professionals as seen by the population, scientists of Public Universities or Public Research Institutes have the highest degree of trustability for the Brazilians citizens ( 0.89 in a scale going from -1 to +1 ), followed by journalists (0.74), doctors $(0.70)$ and writers (0.64). The last position is occupied by politicians $(-0.96)$. Finally, the researchers have done the following question for the population: knowing that the resources of any government are limited and that spending more on some area means having to spend less on other areas, do you believe that the government should increase, maintain or reduce investments in scientific and technological research in the coming years? Increase the investments was the response of $78.1 \%$ of population, while $13.4 \%$ preferred to maintain the investments, and only $3.4 \%$ declared the preference to reduce the investments (4.8\% didn't know and $0.3 \%$ didn't answer). The message is clear.

Finally, maybe the cuts on the budget should be due to some inefficiency, incapacity, low productivity or absence of positive results coming from the Brazilian science. Again, it is necessary to be an extraterrestrial to believe on that. We are full of examples of success and social benefits coming from the Brazilian Science (sugarcane, ethanol as a fuel in automobiles, flex motors, soybean production, the relationship between the zika virus and encephalopathy, EMBRAPA, vaccines, Embraer, extraction of oil from deep well, pre-salt, natural products, new materials, etc. etc. etc.). Before suffering from the recent interruption and decrease of the budget for S,T\&I, Brazil has experimented a continuous growth on both the quantity and quality of the scientific knowledge during the first 14 years of XXI century. New Federal Universities have been created in different regions of the country, the laboratories and equipment infrastructure have been increased and decentralized, the percentage of GDP invested in S,T\&I had slightly increased. Brazil demonstrated his scientific capacity and was ready to give another quality jump. We were responsible for $2.9 \%$ of all the world scientific publication in 2014 , occupying the $13^{\text {th }}$ position between the countries that most published scientific papers. The reality that is still little widespread is that $80 \%$ of all the scientific knowledge produced in Brazil is done by master or PhD students, associated to graduate programs in their large majority (also around $80 \%$ ) in public universities. So, it is impossible to separate the $S$, T\&I from both the graduate system and the public universities. Coincidently, the last three years in which the budget for S,T\&I has been drastically reduced was also characterized by an attack to the public universities, mainly by the Brazilian traditional media conglomerates. TV programs, editorials and articles published in traditional newspapers, containing distorted numbers and distorted information, have been used as an attempt to manipulate the public opinion and support an absurd proposal to become private the Public Universities. Coincidently, the theme suddenly appears to be discussed during the general elections in 2018. Coincidently, the data of different university rankings released by different agencies in Brazil or abroad demonstrating the huge superiority of the public universities when compared with the private ones have not been included in that debates.

Is it really a coincidence?

In another example of the proactive role of SBQ, the editorial of the JBCS published in the issue of October 2016 warned the readers about the coming facts. ${ }^{5}$ With the title "It is Necessary to Resist", it was calling the scientific community to resist against the squeeze, and futuristically affirmed that "taking to account the recent actions, the scenario for the near future tends to get worse." From that time, the scenario unfortunately got worse. It was approved an amend to the Brazilian constitution (EC-95/2016) that freezes all the public investments for the next 20 years. The notes emitted by the presidents of CAPES, CNPq and FINEP that were refereed in the beginning of this editorial describe the reflex of that. For the Brazilian people and the scientific community, the time is now. We have creativity and credibility to turn around. It is necessary to join the efforts of everyone in favor of a huge cause, which is the future and sovereignty of Brazil. It is necessary go beyond political parties, political colors, passions, rancor and polarization. It is necessary to breath above the poisoned environment which is contaminating the current politic scenario. It is necessary to choose representatives that are really compromised with education, science and technology. It is necessary a continuous push over the politicians to rescind the EC-95/2016 and allow the effective growth of the country. As it was claimed two years ago, it is necessary to resist. But more than that, nowadays it is necessary to react.

\section{Aldo José Gorgatti Zarbin Immediate Past-President of Brazilian Chemical Society Universidade Federal do Paraná, Curitiba-PR, Brazil}

\section{References}

1. ISSC, IDS and UNESCO; World Social Science Report 2016, Challenging Inequalities: Pathways to a Just World; UNESCO Publishing: Paris, 2016.

2. Georghiou, L.; Value of Research Policy Paper by the Research, Innovation, and Science Policy Experts (RISE); European Union: Luxembourg, 2015.

3. International Monetary Fund (IMF); Fiscal Monitor: Acting Now, Acting Together, 2016; IMF: Washington, 2016.

4. Centro de Gestão e Estudos Estratégicos (CGEE); A Ciência e a Tecnologia no Olhar dos Brasileiros. Percepção Pública da C\&T no Brasil - 2015; CGEE: Brasília, DF, 2017.

5. Zarbin, A. J. G.; J. Braz. Chem. Soc. 2016, 27, 1705. 